DOI: 10.20472/IAC.2018.040.068

ZUZANA VIRGLEROVA

Tomas Bata University in Zlín, Facutly of Management and Economics, Czech Republic

\title{
DETERMINANTS OF BUSINESS RISKS WITH IMPACT ON SMES IN V4 COUNTRIES
}

\begin{abstract}
:
Many enterprises fight with various risks and it can be a reason of lack of success for their business. The first step towards successful risk management is a risk identification. Entrepreneurs use different methods for risk identification and they also detect diverse risks. The aim of the article is to identify determinants of business risks in SMEs in Visegrad Four. The article deals with the partial results of the empirical questionnaire survey, which was completed in 2018 at the Tomas Bata University in Zlín in the Czech Republic. Questionnaires from the owners of micro and SME enterprises in Hungary (388), Poland (498), Slovakia (487) and Czech Republic (408) were collected. Entrepreneurs were asked for the ability to identify risks, importance of risks and methods used for risk management in their companies. 3 research questions were set in this context. In process of solving the formulated research questions the following statistical tools such as tables, descriptive characteristics, and Person coefficient of contingency were used. Finally, the results indicate that there are differences in risk identification among countries. Also the importance of each risk is different. The similarity of results in Czech Republic and Slovakia was proved. The article concludes with a discussion which explains possible couse of differences and similarities of results.
\end{abstract}

\section{Keywords:}

business risks, SME, entrepreneurship, risk identification

JEL Classification: G32, M21, L26 